\title{
Structural Identification to Improve Bridge Management
}

\author{
James-A. Goulet \\ $\mathrm{PhD}$. Student \\ Swiss Fed. Inst. of Tech. \\ Lausanne, Switzerland \\ James.Goulet@epfl.ch
}

James-A. Goulet, born 1984, received his civil engineering and M. Sc degree from the Univ. Laval.

\author{
Prakash Kripakaran \\ Post-doctoral researcher \\ Swiss Fed. Inst. of Tech. \\ Lausanne, Switzerland \\ Prakash.Kripakaran@epfl.ch \\ Prakash Kripakaran, born 1979, \\ received his masters and \\ doctorate degrees in civil engrg. \\ from North Carolina State Univ.
}

\author{
Ian F. C. Smith \\ Professor \\ Swiss Fed. Inst. of Tech. \\ Lausanne, Switzerland \\ Ian.Smith@epfl.ch \\ Ian F. C. Smith, born 1955, \\ received his civil engineering \\ degree from the Univ. of \\ Waterloo, Canada and his $\mathrm{PhD}$ \\ from the Univ. of Cambridge.
}

\section{Summary}

This paper presents results from static loads tests performed on the new Langensand Bridge built in Switzerland. A systematic study of over 1000 models subjected to three load cases identifies a set of 11 candidate models through static measurements. Predictions using the set of candidate models are homogenous and show an averaged discrepancy ranging of 4 to $7 \%$ from the displacement measurements. All candidate models have values for material proprieties that are close to expected values. This finding confirms that the behaviour of the structure conforms to the design expectations. Comparing the candidate model set to a design model that takes into account only main structural elements shows that the structure has approximately $30 \%$ reserve capacity with respect to a typical deflection risk scenario according to Swiss codes. The population of candidate models may be used to understand and predict the behaviour of the full bridge prior to its completion.

Keywords: Structural Identification, Bridge behaviour, Static Measurement, Multi-Model, data interpretation

\section{Introduction}

Bridges are designed according to codes that specify conservative limits on loading and material properties. Behaviour models used in design, while leading to safe and serviceable structures, are not intended for data interpretation and long-term management of the structure. During the design stage, engineers make conservative assumptions regarding aspects such as the composite behaviour and support conditions. Behaviour models using these assumptions often underestimate the loadbearing capacity of the bridge. Static load-tests may improve in the understanding of real structural behaviour. This paper presents results from static loads tests performed on the new Langensand Bridge in Lucerne, Switzerland.

Static load-tests are not new. Measurements have been used for example to update the flexural stiffness $\boldsymbol{E I}$ of the bridge. However, updating may not bring out reliable information related to the real behaviour of the bridge. An updated model is thus useful only for comparison purposes. Predictions for new load cases or for following the evolution of bridge structural properties (ex: creep) are generally not reliable.

Recent developments in the field of computing allow the use of computation-intensive approaches for interpreting measurements from static load-tests. Many researchers [4-9] have already used static or dynamic measurements to update bridge models. However the uncertainties from measurement, hypothesis and modelling assumptions are seldom considered explicitly. A model that is found by minimizing the difference between predictions and measurements may not be the correct model. Such an approach is justifiable only when there are no errors, which is not feasible for most full-scale engineering challenges. Moreover, since system identification is an inverse approach, many models may predict the same measured behaviour. Raphael and Smith [10] observed that errors in model and measurements may compensate each other. They proposed a 
multi-model approach which involves the generation of thousands of possible behavioural scenarios. Candidate models are selected by comparing the difference between static measurements and predictions with a threshold value that is determined using estimates of modelling and measurement errors (Kripakaran et al. 2007; Robert-Nicoud et al. 2005).

Building on previous research, this paper presents results of the multi-model system identification approach applied to a new bridge. The approach is used to analyze measurements from static loadtests on Langensand Bridge. Instead of searching for a single model that exactly matches the behaviour of the structure "as tested", the approach aims to identify a set of candidate models such that any model from the set may explain measured behaviour. Several thousand finite element simulations are performed to identify a good set of candidate models. Uncertainty contributions from all sources are evaluated. Based on the evaluated uncertainties, threshold values are estimated for the candidate models. To evaluate the effectiveness of the multi-model approach, the candidate models are compared to the design model and a model obtained from model updating.

The following section describes the multi-model approach and how it is applied to the Langensand bridge case. Section three of this paper gives a general description of the load tests. It contains information about the type of acquired data, model generation and uncertainties. Section four presents results from structural identification.

\section{System identification using multi-model approach}

The multiple-model system identification method developed at EPFL is based on the hypothesis that modelling and measurement errors may compensate each other. Therefore this approach finds a set of candidate models such that the difference between model predictions and measurements are less than a threshold value that depends upon modelling and measurement uncertainties. The framework of multiple-model system identification research at EPFL $[11,12]$ is shown in Figure 1.

Prior to load tests, thousands of a-priori behavioural models are generated based on engineers' design hypothesis and assumptions. The set of model parameters may consist of quantities such as elastic constant, bearing device stiffness and section thickness. Based on this a-priori model set, sensors are placed at location given by an algorithm previously developed at EPFL [1-3]. The objective of this process is to find sensor types and locations that will separate (i.e. identify) the largest number of candidate models.

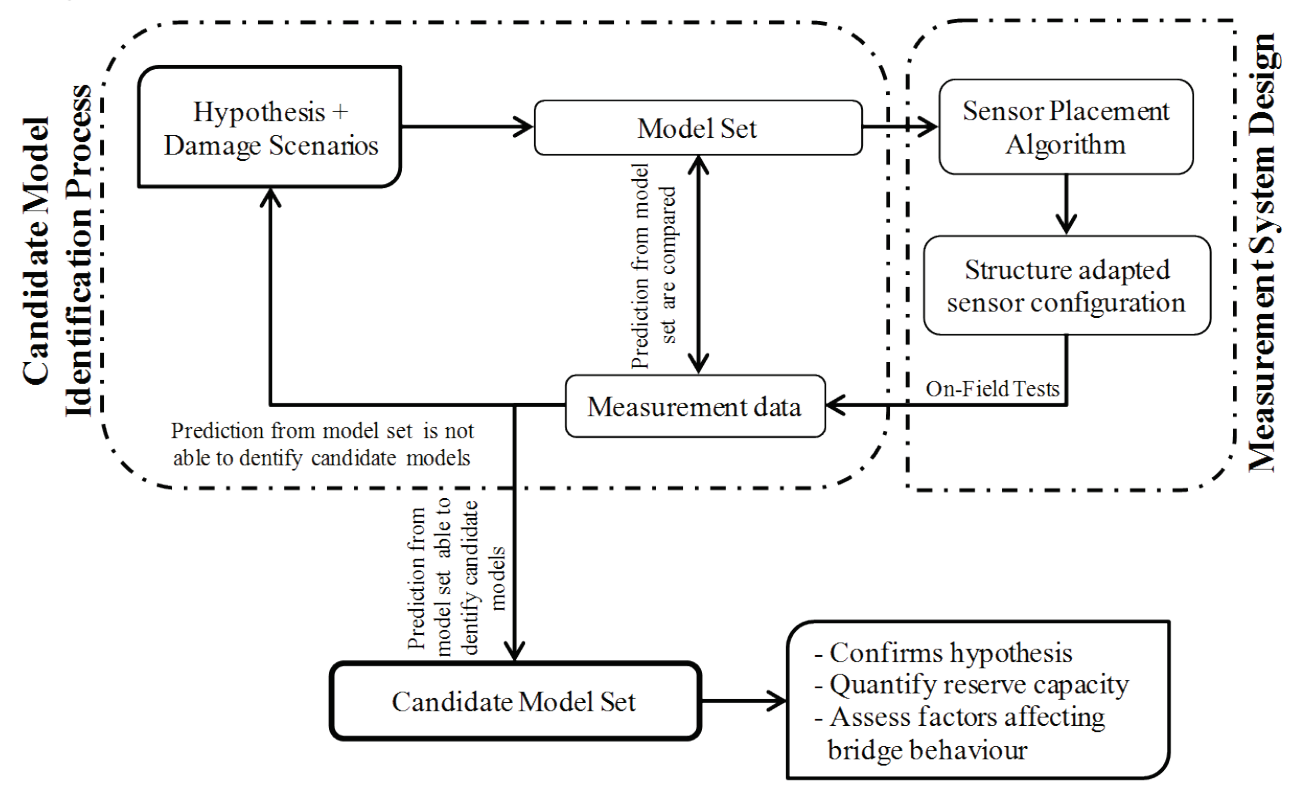

Figure 1 - Framework for multi-model system identification

After the initial measurement system design, data is acquired from field tests. During these tests, every significant uncertainty sources are assessed (temperature effect, truck positioning, truck 
weight, sensor accuracy, bridge linear behaviour, etc). The contributions from each source are combined with modelling uncertainties, and a threshold value that is specific to each sensor and each load case is obtained. This threshold value determines whether or not a model is selected as a candidate.

The identification process is iterative. If no candidate models are identified or if new facts are discovered from the identification process, the initial hypotheses are modified and new models are generated. The predictions coming from the new set are then compared to the measurement data. When candidate models are found, they may be used to confirm or reject initial hypotheses, quantify bridge reserve capacity and assess factors affecting bridge behaviour.

\section{Case study: Structural system identification of Langensand Bridge}

The new Langensand Bridge in Lucerne (Switzerland), is being built in two phases to avoid traffic interruption on the existing bridge. Load tests were performed after the completion of the first phase when only a half of the bridge was built. Understanding the structural behaviour of this bridge is not straight forward due to its high slenderness ratio $(>\mathrm{L} / 30)$, a cross section of non-uniform shape and the presence of an important skew at abutments. Sensors selected to perform the static-load tests are: displacement measurements taken in six locations with optical devices, two inclinometers placed near the abutment and fibre-optic sensors placed at five locations on the bridge. Figure 2 shows the finite element model created for the Langensand Bridge. A detailed cross-section of the bridge is presented in Figure 3.

A population of models is generated from a general numerical model to which combinations of several features such as partial composite interaction, bearing device restraint, element thickness and material proprieties are added. The population is generated using the Latin Hypercube

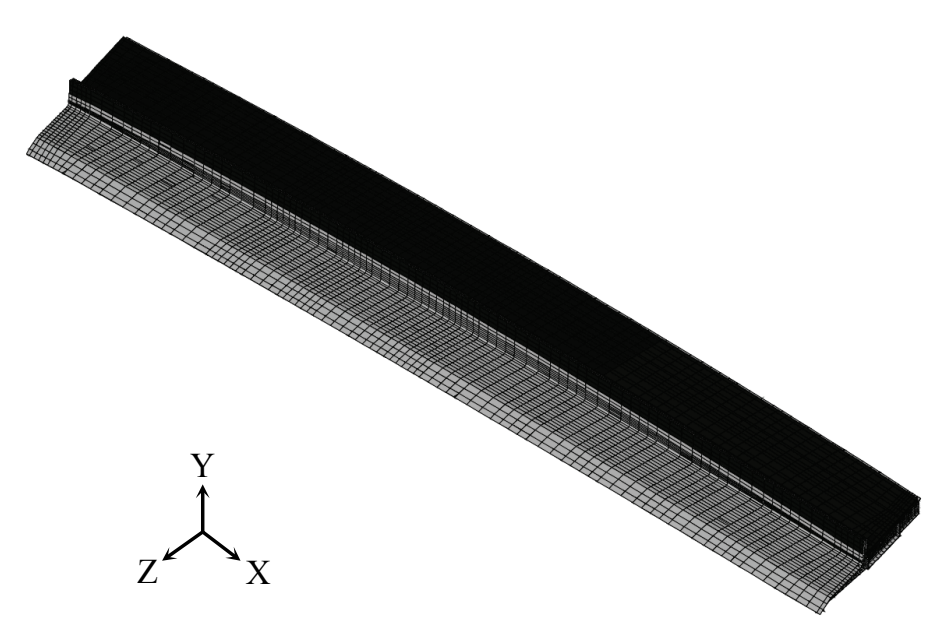
Sampling method implemented in ANSYS [13]. The main parameters and features used as input are: stiffness of the bearing devices, level of composite interaction between steel girder and concrete deck and values for parameters such as material proprieties, plate thickness and sensor positioning. In addition to test cases used to validate the models, a set of 1000 models is used to assess the bridge behaviour. Each model is analysed for the three load cases. Separately, a set composed of 4000 models is used to determine whether or not the concrete deck is behaving in a fully composite manner.

Figure 2 - Finite element model of the first half of Langensand bridge

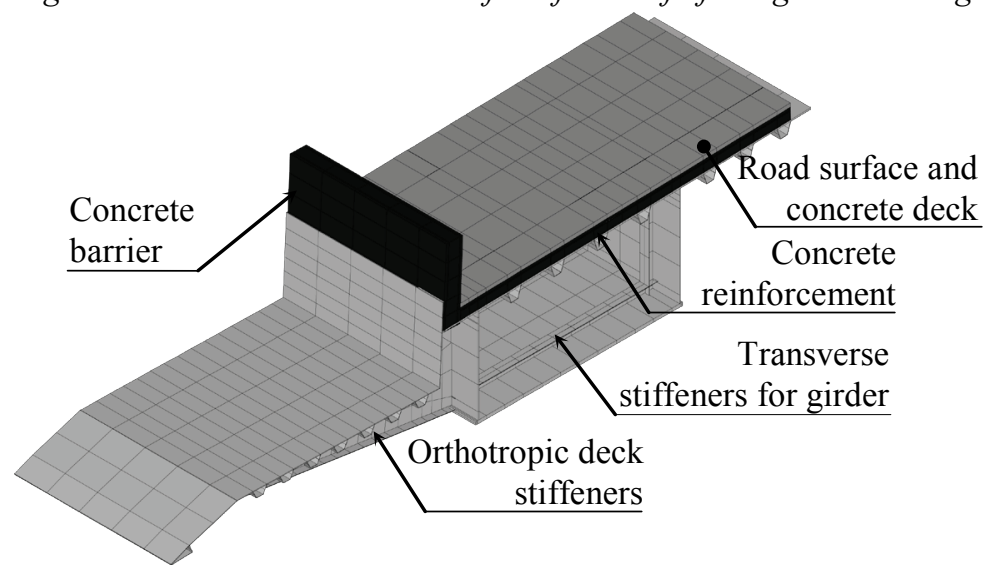

A general model of the bridge is implemented using ANSYS Parametric Design Language (APDL) [13]. The geometry used in the model is based on the as-built geometry of the structure. In addition to the main load-bearing components, the model also includes secondary elements that significantly affect the behaviour of the bridge (i.e. sidewalk, barrier, road surface, stiffeners, reinforcing steel and bracing).

Figure 3 - Cross-section of the first half of Langensand bridge

Research studies [14-18] have already underlined the importance of these elements on the 
behaviour of a structure. Elements that were present during the tests and excluded from the model include the wooden protection barriers present on each side of the bridge, the mechanical tubing present into the girder and the light posts.

\subsection{Uncertainties}

Uncertainties identified during the tests have several sources. The ones that have a significant effect on the results come from: measurement, modelling and uncertainties in fundamental hypotheses. This section describes how each uncertainty type is assessed or minimized.

\subsubsection{Measurement Uncertainties}

The sensor accuracy is given in the resolution specifications from the manufacturer. In the case of electrical devices (i.e. inclinometers) the sensor accuracy has been taken to be twice the specified resolution to take into account cable and contact losses as well as site conditions. The movement from ambient vibrations of the bridge are filtered out by taking an average value over multiple samples. In-between each measurement and the application or removal of loads on the bridge, a time interval without activity of one minute is allowed for the attenuation of vibrations. The upper bound for the errors associated with truck positioning is computed since each load case is repeated three times. A factor of three applied to the standard deviation of the result of a given load case provides a confidence level of approximately $97 \%$. The variations in the truck weights have a linear influence on the structure. Uncertainties caused by this variation account for a possible discrepancy of 0.5 ton over the weight of a single truck. Temperature effects are eliminated by taking measurements over a short period of time for each load case.

\subsubsection{Modelling Uncertainties}

Modelling experience and judgment are used to reduce uncertainties that originate from using the finite element method (FEM). Mesh discretization accuracy is estimated using preliminary studies made at IMAC. Uncertainties in geometry are eliminated by using a numerical model that uses dimensions taken from the "as-built" structure.

\subsubsection{Hypothesis Uncertainties}

Bearing devices and loads are assumed to be concentrated loads. This simplification of the real structure is valid only if the results are used for understanding the global behaviour of the bridge.

Figure 4 gives the averaged contributions of all uncertainty types for each type of sensor. The main uncertainty sources are summarized and quantified in Table 1.

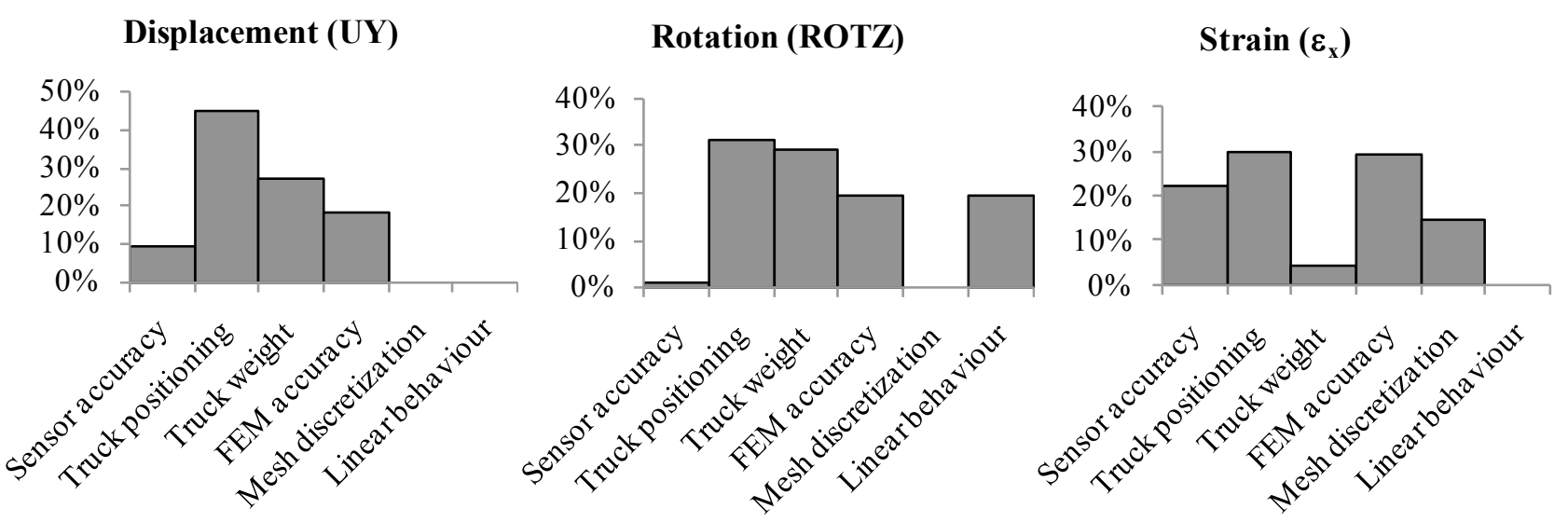

Figure 4-Contributions of the uncertainty types to the three measured quantities 


\begin{tabular}{|c|c|c|c|c|c|}
\hline \multirow{2}{*}{\multicolumn{2}{|c|}{ Error Sources }} & \multirow{4}{*}{$\begin{array}{l}\text { Quantification Method } \\
\text { Manufacturer specified resolution }\end{array}$} & \multicolumn{3}{|c|}{ Error According to the Type of Measurement } \\
\hline & & & Displacement & Rotation & Strains \\
\hline \multirow{6}{*}{ 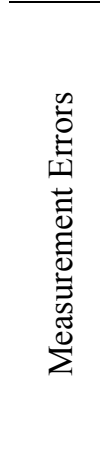 } & Sensor accuracy & & $\pm 0.1 \mathrm{~mm}$ & $\pm 2.2 \times 10^{5 \circ}$ & $\pm 2 \mu \varepsilon$ \\
\hline & & & $\pm[0.4-0.8] \%$ & $\pm[0.2-0.3] \%$ & $\pm[4-14] \%$ \\
\hline & $\begin{array}{l}\text { Sensor Noise from Ambient } \\
\text { Vibration of the Bridge }\end{array}$ & Average taken over multiple samples & $\rightarrow 0 \%$ & $\rightarrow 0 \%$ & $\rightarrow 0 \%$ \\
\hline & Truck Positioning & $\begin{array}{l}\text { Use value from multiple samples } \\
\text { to determine a maximum error }\end{array}$ & $\begin{array}{l} \pm 3 \sigma \\
\pm[1-5] \%\end{array}$ & $\begin{array}{l} \pm 3 \sigma \\
\pm[1-3] \%\end{array}$ & $\begin{array}{l} \pm 3 \sigma \\
\pm[2-16] \%\end{array}$ \\
\hline & Truck Weight & $\begin{array}{l}\text { The truck weight variations have } \\
\text { a linear response on the structure }\end{array}$ & $\approx \pm 1.5 \%$ & $\approx \pm 1.5 \%$ & $\approx \pm 1.5 \%$ \\
\hline & Temperature Effects & $\begin{array}{l}\text { Measurements for each load case } \\
\text { taken over a short period of time }\end{array}$ & $\rightarrow 0 \%$ & $\rightarrow 0 \%$ & $\rightarrow 0 \%$ \\
\hline \multirow{5}{*}{ 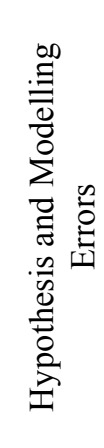 } & Finite Element Method & $\begin{array}{l}\text { Approximate value based } \\
\text { on experience }\end{array}$ & $\approx \pm 5 \%$ & $\approx \pm 5 \%$ & $\approx \pm 5 \%$ \\
\hline & Mesh Discretization & Based on a preliminary study & $\approx 0 \%$ & $\approx 0 \%$ & $\approx \pm 5 \%$ \\
\hline & Model Exactitude & Model "as built" & $\rightarrow 0 \%$ & $\rightarrow 0 \%$ & $\rightarrow 0 \%$ \\
\hline & $\begin{array}{l}\text { Bearing Devices Represented } \\
\text { as Point Loads }\end{array}$ & $\begin{array}{l}\text { Negligible effect on the global } \\
\text { behaviour of the structure }\end{array}$ & $\rightarrow 0 \%$ & $\rightarrow 0 \%$ & $\rightarrow 0 \%$ \\
\hline & $\begin{array}{l}\text { Truck Wheels Considered as } \\
\text { Point Loads }\end{array}$ & $\begin{array}{l}\text { Negligible effect on the global } \\
\text { behaviour of the structure }\end{array}$ & $\rightarrow 0 \%$ & $\rightarrow 0 \%$ & $\rightarrow 0 \%$ \\
\hline
\end{tabular}

\section{Results}

Candidate models representative of the measured behaviour are presented in Table 2. From a model set (composed of 1000 models) 11 candidate models are identified from static measurements. The predictions from the candidate set correspond to the displacement and rotation measurements with an average accuracy ranging from $4 \%$ to $7 \%$. Strains are more difficult to assess. The deviations range from 15 to $22 \%$ compared with measurements. The predictions from the model set provide ranges within which the real behaviour of the structure is expected. The following section shows how the candidate model set is built.

Table 2 - Identified set of candidate models

\begin{tabular}{|l|l|l}
\hline $\begin{array}{l}\text { Variation in } \\
\text { thickness (\%) }\end{array}$ & $\begin{array}{l}\text { Young's Modulus } \\
(\mathrm{GPa})\end{array}$ & $\begin{array}{l}\text { Averaged prediction/ } \\
\text { measurement ratio }\end{array}$
\end{tabular}

Model Road Road Displacement

\# $\quad$ Steel Concrete surface Steel Concrete surface \& Rotations Strains

\begin{tabular}{lccccccc}
\hline 1 & $0 \%$ & $3 \%$ & $-13 \%$ & 210.236 .8 & 1.8 & 1.06 & 1.20 \\
2 & $1 \%$ & $1 \%$ & $48 \%$ & 206.639 .2 & 1.5 & 1.05 & 1.18 \\
3 & $0 \%$ & $-1 \%$ & $-16 \%$ & 210.736 .5 & 1.6 & 1.07 & 1.22 \\
4 & $1 \%$ & $1 \%$ & $-27 \%$ & 208.337 .9 & 2.5 & 1.05 & 1.19 \\
5 & $0 \%$ & $1 \%$ & $13 \%$ & 211.935 .8 & 2.4 & 1.07 & 1.23 \\
6 & $0 \%$ & $1 \%$ & $-15 \%$ & 211.938 .7 & 0.8 & 1.05 & 1.17 \\
7 & $1 \%$ & $2 \%$ & $2 \%$ & 210.537 .9 & 1.2 & 1.05 & 1.19 \\
8 & $1 \%$ & $-1 \%$ & $7 \%$ & 211.738 .6 & 2.4 & 1.04 & 1.18 \\
9 & $0 \%$ & $-1 \%$ & $-6 \%$ & 211.241 .7 & 1.1 & 1.04 & 1.15 \\
10 & $1 \%$ & $3 \%$ & $13 \%$ & 211.736 .9 & 1.4 & 1.06 & 1.20 \\
11 & $-1 \%$ & $3 \%$ & $28 \%$ & 211.538 .4 & 1.4 & 1.05 & 1.18 \\
\hline
\end{tabular}

the behaviour of the structure.
Candidate models are those for which the discrepancy between predicted and measured values for each sensor and each load case lie between threshold bounds. This process is illustrated in Figure 5 where model predictions are plotted against to their discrepancy relative to the measured value. In each plot, the dotted lines indicate threshold bounds. Each point represents a model. Candidate models are shown by a plus marker. The figure shows that models minimising the discrepancy to 0 for one or even several measurements are not always the best models to explain 


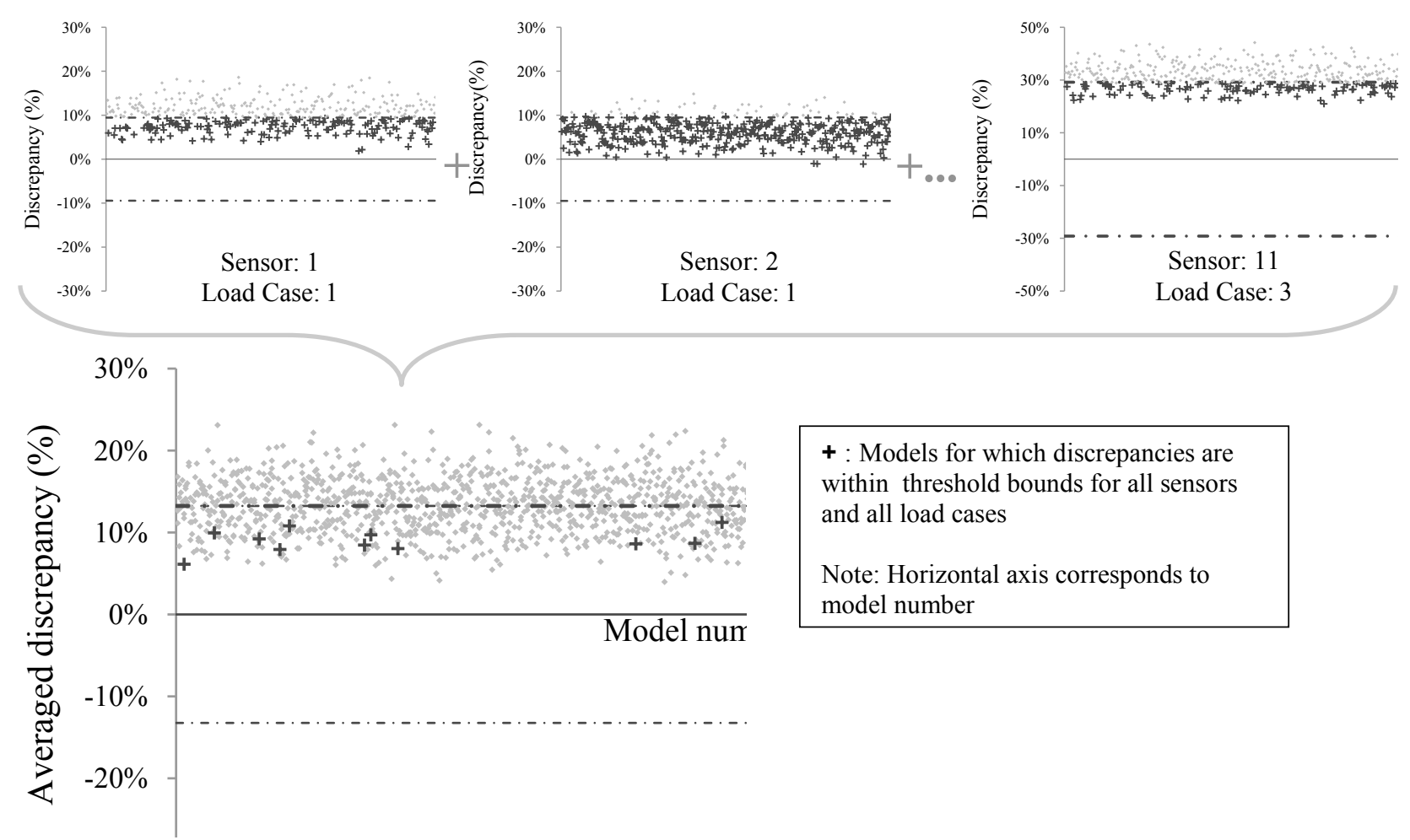

Figure 5 - Candidate model selection using threshold values. Each point represents the percentage difference between predictions and measurements from one model.

Results from measurements show no signs of a partial interaction between the concrete deck and the steel girder. Models representing a partial composite interaction have unrealistic material proprieties to compensate for the additional flexibility introduced by this feature. Oehlers and Bradford [19] report that "all composite beams with mechanical shear connectors exhibit partial interaction, since the mechanical shear connectors have to slip before they resist shear". Therefore, while the effect may be present, it is not significant enough to be distinguished from fully composite interaction and therefore it would not significantly alter the in-service behaviour of the structure.

\subsection{Improvement over classical model updating}

Predictions from the design model, a model obtained by model updating and models from multimodel approach are compared for the risk situation $E_{d}(1)$ prescribed in the SIA standard [20].

$$
E_{d}=0.75 \cdot L_{\text {Lane }}+0.40 \cdot L_{\text {Sidewalk }}
$$

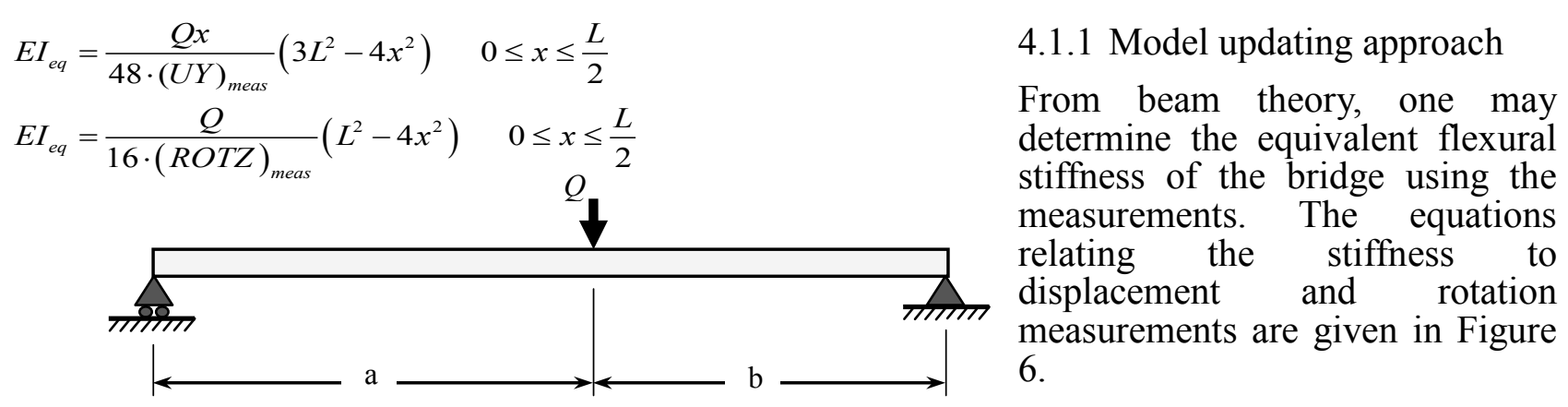

Figure 6-Beam model used for model updating

Measurements from one load case are used to compute the equivalent flexural stiffness of the bridge. Using the four measurements and the equations presented in Figure 6, the average flexural stiffness 
is evaluated as $2.75 \times 10^{17} \mathrm{~N} \cdot \mathrm{mm}^{2}$

\subsubsection{Comparison of approaches}

The stiffness estimated using model updating is used to predict the maximal displacement of the bridge under the risk situation $E_{d}$. Results are shown in Table 3 . The table also includes the predictions of (i) the candidate models from the multi-model approach and (ii) the design model.

$\underline{\text { Table } 3 \text { - Vertical displacements under SIA risk situation } E_{d}}$

\begin{tabular}{|c|c|c|}
\hline Approach & $\begin{array}{l}\text { Maximum vertical displacement } \\
\text { for risk situation } E_{d}(\mathrm{~mm})\end{array}$ & $\begin{array}{l}\text { The results show that simple model updating is } \\
\text { not appropriate since it underestimates the }\end{array}$ \\
\hline Updated model & 73.0 & $\begin{array}{l}\text { vertical displacement. The design-model is safe } \\
\text { and conservative. Results from Tables } 3 \text { also }\end{array}$ \\
\hline Multi-model & $82.1-84.5$ & show that the bridge has a reserve deflection \\
\hline Design-model & 117.8 & $\begin{array}{l}\text { ty that is approximately } 30 \% \text { more th } \\
\text { dacity given by the design model. }\end{array}$ \\
\hline
\end{tabular}

\section{Conclusion}

The conclusions of this research are:

- The tests demonstrate the applicability of the multi-model approach for structural identification of bridge structures. It shows that models generated by model updating may be unreliable. Simple model updating may be unsafe since structural capacity may be overestimated.

- Generation and reasoning with set of candidate models improve the understanding of the bridge behaviour. The example in this paper showed that these models are able to predict the service behaviour to within $7 \%$ of measured values.

- Comparing the candidate model set to the initial design model that only takes into account main structural elements shows that the structure has approximately $30 \%$ reserve deflection capacity.

- The results show that there is full composite interaction between the concrete slab and the steel girder. While partial interaction may be present locally, it has negligible impact on the global service behaviour of the structure.

Future work will focus on assessing the modelling uncertainty associated with using shell elements to model bridge behaviour. Also, studies using new statistical approaches are underway to rank the candidate models according to their probability of representing the structure. Ranking models would allow combining a-priori knowledge of structural parameters with model identification.

\section{Acknowledgements}

Collaboration with the designers of the Langensand Bridge - Gabriele Guscetti and Claudio Pirazzi (Guscetti \& Tournier), was important for successful completion of the load tests. The authors also acknowledge input from Dr. R. Cantieni and the help we received from his team when taking the measurements. Finally the authors would like to thank - I. Laory and P. Gallay for their help during load testing. The city of Lucerne provided logistics support, the trucks for the load tests and the deformation sensors. This research is funded by the Swiss National Science Foundation under contract no. 200020-117670/1.

\section{References}

[1] KRIPAKARAN, P., et al., Optimal sensor placement for damage detection: Role of global search. Dexa 2007: 18th International Conference on Database and Expert Systems Applications, Proceedings, ed. A.M. Tjoa and R.R. WAGNER. 2007, Los Alamitos: Ieee Computer Soc. 302-306.

[2] KRIPAKARAN, P., et al. Measurement System Design Using Damage Scenarios. in ASCE International Workshop on Compution in Civil Engineering. 2007: ASCE. 
[3] ROBERT-NICOUD, Y., B. RAPHAEL, and I.F.C. SMITH, Configuration of measurement systems using Shannon's entropy function. Computers \& Structures, 2005. 83(8-9): p. 599-612.

[4] SCHLUNE, H., et al, Improved bridge evaluation through finite element model updating using static and dynamic measurements. Engineering Structures. 2009. 31(7): p. 1477-1485.

[5] BELL, E.S., et al., Multiresponse parameter estimation for finite-element model updating using nondestructive test data. Journal of Structural Engineering-Asce, 2007. 133(8): p. 1067-1079.

[6] MORASSI, A. and S. TONON, Dynamic Testing for Structural Identification of a Bridge. Journal of Bridge Engineering, 2008. 13(6): p. 573-585.

[7] BAKHTIARI-NRJAD, F., A. RAHAI, and A. ESFANDIARI, A structural damage detection method using static noisy data. Engineering Structures, 2005. 27(12): p. 1784-1793.

[8] HE, X., et al., System Identification of Alfred Zampa Memorial Bridge Using Dynamic Field Test Data. Journal of Structural Engineering, 2009. 135(1): p. 54-66.

[9] PAUlO J. S. CRUZ, R.S., Performance of Vibration-Based Damage Detection Methods in Bridges. ComputerAided Civil and Infrastructure Engineering, 2009. 24(1): p. 62-79.

[10] RAPHAEL, B. and I. SMITH, eds. Finding the right model for bridge diagnosis. Artificial Intelligence in Structural Engineering in Computer Science. Vol. LNAI 1454. 1998, Springer: Heidelberg. 308-319.

[11] SMITH, I.F.C. and S. SAITTA, Improving knowledge of structural system behavior through multiple models. Journal of Structural Engineering-Asce, 2008. 134(4): p. 553-561.

[12] ROBERT-NICOUD, Y., et al., Model identification of bridges using measurement data. Computer-Aided Civil and Infrastructure Engineering, 2005. 20(2): p. 118-131.

[13] ANSYS, Theory Reference for ANSYS and ANSYS Workbench. 2007, ANSYS, Inc.: Southpointe.

[14] MASBOUT, M.E., et al., Influence of Sidewalks and Railings on Wheel Load Distribution in Steel Girder Bridges. Journal of Bridge Engineering, 1997. 2(3): p. 88-96.

[15] EAMON, C.D. and A.S. NOWAK, Effects of Edge-Stiffening Elements and Diaphragms on Bridge Resistance and Load Distribution. Journal of Bridge Engineering, 2002. 7(5): p. 258-266.

[16] EAMON, C.D. and A.S. NOWAK, Effect of secondary elements on bridge structural system reliability considering moment capacity. Structural Safety, 2004. 26(1): p. 29-47.

[17] CHUNG, W., J. LIU, and E.D. SOTELINO, Influence of Secondary Elements and Deck Cracking on the Lateral Load Distribution of Steel Girder Bridges. Journal of Bridge Engineering, 2006. 11(2): p. 178-187.

[18] AKIINCI, N.O., J. LIU, and M.D. BOWMAN, Parapet Strength and Contribution to Live-Load Response for Superload Passages. Journal of Bridge Engineering, 2008. 13(1): p. 55-63.

[19] OEHLERS, D.J. and M.A. BRADFORD, Composite Steel and Concrete Structural Members, ed. PERGAMON. 1995, Guildford: Elsevier Science Ltd. 546 p.

[20] SIA, Actions sur les structures porteuses, in SN 505 261. 2003: Zurich. p. 104 p. 